INTERNATIONAL DESIGN CONFERENCE - DESIGN 2018

https://doi.org/10.21278/idc.2018.0536

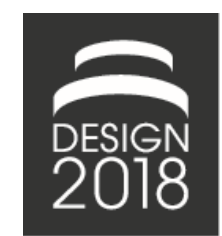

\title{
THE DESIGN OF VISUAL INFORMATION OBJECTS IN THREE-DIMENSIONAL VIRTUAL ENVIRONMENTS FOR ENGINEERING INFORMATION NAVIGATION
}

\author{
D. E. Jones, C. Snider, J. Yon, J. Gopsill, Y. Xie, N. Chanchevrier and B. Hicks
}

\begin{abstract}
Product Life-Cycle Management (PLM) and Product Data Management (PDM) systems aim to facilitate the capture and dissemination of information throughout the product life-cycle by providing an artefactcentric approach to Information Management. Work is progressing in providing three dimensional artefact-based user interfaces to PLM/PDM and in contribution to this field, this paper describes the design and verification or a number of Visual Information Objects (VIO), visual markers that indicate the presence of information within the three dimensional artefact space.
\end{abstract}

Keywords: product lifecycle management (PLM), product data management (PDM), visualisation, information retrieval, information management

\section{Introduction}

Product Life-Cycle Management (PLM) and Product Data Management (PDM) systems aim to facilitate the capture and dissemination of information throughout the product life-cycle (Ameri and Dutta, 2005; Stark, 2015). These systems have been created to place the product at the heart of day-to-day operation and allow organisations to operate in a truly product-centric manner (Ameri and Dutta, 2005; Tursi et al., 2009). Annotated Computer Aided Design (CAD) builds on this concept by directly attaching information such as design rationale to the CAD model (McMahon and Davies, 2006; Ding et al., 2009; $\mathrm{Li}$ et al., 2009). In a similar fashion, Building Information Management (BIM) systems create a digital representation of 'real world' buildings and tag the virtual model with information such as the location and descriptions of maintenance works performed. Liu and Xu (2001) reviews web-based PDM systems and the authors work in Jones et al. (2015) introduces a strategy that takes this concept a step further by placing a three-dimensional artefact at the heart of web-based document search or navigation, where a set of results are filtered based on the manipulation of a lightweight CAD model within a web browser. The goal of each of these systems is to improve the access and dissemination of information via a computer generated graphical representation of the product (Virtual Environment (VE)).

While work in this area is progressing and the fundamentals of design theory underpin many aspects of graphical implementations, approaches and best practices on the visual representation of information markers or objects within engineering VEs has yet to be concluded.

The placement of markers within three-dimensional environments, whether virtual or not, requires careful consideration. Consider road traffic signs as an example; the UK government's Department for Transport publishes an eight-chapter manual (Department for Transport, 2009) that covers every detail of the road signs that most drivers will pass without giving them a second thought. The purpose of road traffic signs is to disseminate information with maximum ease and intuitiveness such that the driver 
receives and processes information while travelling at high speeds with relatively little cognitive effort. Consequentially, the effectiveness of information visualisations such as road signs is an argument for a high benchmark in the visual representation of information in three-dimensional environments.

The UK Department for Transport achieves such a high standard by designing from the fundamentals of design theory and applying them to very specific use cases. The work presented in this paper outlines a similar journey with the aim of producing a number of strategies for generating Visual Information Objects (VIOs) within engineering VEs. VIOs being graphical markers or icons located in the VE that disseminate the existence and location of information within the three-dimensional space. This paper begins with a more complete description of engineering VEs and the need to capture and represent engineering information. Then, some of the relevant fundamentals of design theory are covered. A set of use cases are then distilled based on a range of discussions with industrial and academic engineers. The theory and use cases are then combined and a number of VIOs are proposed before being evaluated through an end user study.

\section{Background}

This section outlines the background engineering VEs, three-dimensional computer-generated visualisations and the current practices for the display of information within them.

\subsection{Engineering Virtual Environments}

Ellis $(1991,1994)$ defines VEs as interactive graphical displays that are sometimes enhanced with audio or haptic feedback. For the purposes of this study, engineering VEs are considered to be interactive graphical environments that support the engineer with engineering tasks. Engineering VEs are then product-centric and allow for the design, drafting and testing of virtual artefacts. Computer Aided Design (CAD) systems being the most obvious example. Other examples include combining CAD with virtual reality (Kim and Weissmann, 2006), virtual assembly (Jayaram et al., 1999) and distributed virtual environments that allow engineers based at various locations to collaborate via their own perspectives (Maxfield et al., 1995).

Augmented Reality (AR) systems mix VEs with the real world by overlaying computer generated images. Engineering examples include AR for manufacturing, planning, training and architectural construction, and inspection and renovation (Webster et al., 1996; Doil et al., 2003; Liarokapis et al., 2004). As a sibling research field to VE, there are many elements of AR research, such as information visualisation and the design of labels, that can be directly applicable to VEs.

CAD packages cater for both two-dimensional and three-dimensional drawings with standards extending from traditional pencil and paper drafting. Two-dimensional drawings rely heavily on a small number of basic visual building blocks (predominantly line and text) and use them in a very precise and controlled manner (BSI Group, 2004).

The combination of lines and text form VIOs that appear highly efficient in their dissemination of engineering information. In the wider VE/data visualisation fields these VIOs are categorised as External Labels. Labels in VEs are categorised as either Internal or External. Internal or Surface Labels are those more associated with maps and are written on the surface of visual objects or 'spatially bound' to an object (Vaaraniemi et al., 2013). External Labels are more associated with engineering drawings (BSI Group, 2004) with labels being placed surrounding the visual object and coupled with lines to convey the connection between label and object. These labels are also standardised across threedimensional drawings through the ASME Y14.41 and ISO 16792 international standards.

Based on the prevalence use of External Labels in engineering their wider use outside of the CAD package could be argued. However, non-engineering VEs and AR examples have shown their use can cause the VE to become cluttered and give rise to issues of occlusion. To overcome this, view management techniques are implemented to manipulate the positioning of labels and connecting lines based on the orientation of the user (Bell et al., 2001; Tatzgern et al., 2014). The alternative is to separate the text from the VIO and use an icon to identify position, similar to those used in Geo-Information Systems (GIS) such as the Google Maps pin (Svennerberg, 2010). Icons, when well designed, can aid the efficient disseminate information (Horton, 1994). 


\subsection{Engineering Information Management across product life-cycles}

Hicks et al. (2002) discusses data, information and knowledge and their relations within the context of engineering design, outlining their importance before describing a formal framework. Engineering Information Management (EIM) then aids the efficient capture and dissemination of information in support of business processes, whether they be software application or business processes/practices themselves (Rangan and Chadha, 2001).

Engineering information usage can range from supplier information to records of previous designs (Allen et al., 2000) recorded in the forms of written notes, sketches and printed CAD drawings with annotations to name a few examples (McAlpine et al., 2006). A whole life-cycle approach to engineering and engineering information can improve the engineering process, for example, a product's end of life condition data being fed back into the design and manufacture to produce a more robust evolution of the design (Pnueli and Zussman, 1997). It is here where Product Life-Cycle Management and Product Data Management systems aim to facilitate the capture and reuse of information to maximise data reuse, knowledge discovery and consequentially the performance of the product itself.

One of the key features of EIM, whether handled by a dedicated PLM/PDM system or not, is the finding and re-finding of information via a search engine (Ameri and Dutta, 2005). While current enterprise search applications can struggle to match the performance of those of the internet (Hawking, 2004), work is progressing to better understand the challenges of enterprise search and its improvement (Giess et al., 2008; Xie et al., 2011; Jones et al., 2016). Jones et al. (2015) outlines a visual strategy to enable such improvement, based on the premise that engineers think visually and functionally, the authors describe a strategy for the navigation of engineering information via a three-dimensional artefact. An important area that is not considered by Jones et al. (2015) is that of user experience/interface design and, in particular, the best or most appropriate way to visually represent information given the user and use case. This is the challenge addressed in this paper.

\subsection{Engineers and complex engineering artefacts}

Websites such as https://www.thingiverse.com/ and https://grabcad.com/ are representative of the vast ranging varieties of artefacts drawn in CAD systems. Artefacts vary in shape from circular to square, naturally inspired to highly engineered and from simple single components to massive multi-component and multi-system assemblies. As part of an exploration of the world of PLM, Stark (2015) examines the typical number of parts in various products, listing a can of deodorant having 20 parts, a car having 25,000 parts and an aircraft having 40,000 parts. From these it can be said that the engineer can then be faced with any number, size, shape and complexity of artefact when interacting with engineering VEs. For these reasons, designing VIOs that are distinct from the artefact and instinctively seen by the user with minimal cognitive load is nontrivial.

\section{User considerations}

The role of the user in Human Computer Interaction (HCI) is a maturing field with a vast range of best practices and considerations documented (Few, 2006; Galitz, 2007; Shneiderman et al., 2010). This section highlights some of the most applicable user considerations for engineers and engineering VEs that apply to the design of engineering VIOs.

\subsection{Memory load}

Memory load is the cognitive effect required to interact with the display. The user should not have to remember information between actions. One method of achieving this is to design tasks and actions that take only a small number of steps to complete. The environment should be designed for both novice and experienced users. A novice user will require labels providing more detail while experienced users should be provided with short cuts (Smith and Mosier, 1984; Shneiderman et al., 2010).

\subsection{Information assimilation}

Information assimilation should be easy for the user and a good environment should facilitate this. The environment should assist rather than inhibit the user's ability to view and understand the information 
being displayed. Techniques for achieving this include formatting the display in a fashion that is familiar to the user and in a way that is suitable to the task, tables of columns and rows for numerical data for example (Smith and Mosier, 1984; Shneiderman et al., 2010).

\subsection{Information foraging}

Information foraging highlights the behavioural similarities between users searching for information and animals foraging for food (Pirolli and Card, 1999). Users are said to follow information scents that steer the path of the search towards an information goal and switch between scents when a particular path is proven fruitless. How Information foraging works within a VE is highly dependent on the nature of the VE. The system outlined by Jones et al. (2015) for example highly constricts the 'scent' to the product structure.

\subsection{User control}

User control makes the user a participant in the visualisation. Galitz (2007) and Shneiderman et al. (2010) both advocate the user being given control of various aspects of the display with Shneiderman et al. (2010) stating the importance of maintaining the user's sense of locus control in dialogue design. Galitz (2007) states that control is achieved when a person, working at his or her own pace, can determine what to do, how to do it and is then easily able to get it done.

\section{Design considerations}

One of the most significant challenges addressed in this paper is creating VIOs that are distinct from the VE itself. AR implementations achieve this with relative ease as a computer generated VIO graphic will clearly stand out against a real-world background. Much of the current AR research focuses on the relative positioning of VIOs, occlusion and readability of text (Bell et al., 2001; Gabbard et al., 2006). Each of these is highly applicable to VIOs in VEs and so any solution must adhere to the best practices of each of these (as well as design in general). The following sections set out the primary design considerations, with example and best practices highlighted throughout.

\subsection{Colour}

Colour is one of the most powerful yet often misused building blocks of visualisation (Few, 2006). It can be soothing to the eye, liven a dull visualisation, encode discrete values, reinforce logical organisations, draw attention, evoke emotional responses and highlight/create relationships (Few, 2006; Shneiderman et al., 2010) but when used incorrectly it can distract or insufficiently highlight important information (Few, 2006). To counter this, Shneiderman et al. (2010) advocates designing in monochrome first and then adding colour and, in line with Shneiderman et al. (2010) and Galitz (2007), the author repeatedly highlights that colour should be used sparingly, thoughtfully and simply. For the purpose of highlighting information within engineering VEs, a VIO within the VE must be coloured such that it appears distinct from the VE.

\subsection{Shape}

Shape is one of the core building blocks of information visualisation. It is useful for labelling and encoding categories but can have significant cultural connotations (a cross for example) that should be taken into consideration (Shneiderman et al., 2010).

When examining shape in visualisations it is useful to de-construct some of our more common information visualisations. The bars on a bar chart are rectangles whose lengths reflect quantitative data and a pie chart is a circle that represents the whole of something that is divided up into parts. Shapes can be bound directly to data in this way to allow for the direct visualisation of information (Dewar, 2012).

Within engineering VEs, using shape to form distinct VIOs is not a straight forward solution. Given that a CAD engineer can be designing many free form regular shaped parts, there is no single means to generate a VIO that will always be both consistent in shape and distinct to the VE.

\subsection{Size}

Size can be perceived as the importance or magnitude of an entity/value. The larger an entity the more important the entity or the larger the underlying data. The human mind is good at comparing the area of 
a rectangle when the length changes (as in bar graphs) but struggles when both length and width are varied at the same time. In the same vein, users struggle to comprehend the differences in the areas of circles although circles are good at providing coarse representations (Iliinsky and Steele, 2011).

Within the context of VEs, size suffers from the same problem as shape in that there is no way of determining in advance the relative sizes of parts particularly in large sub-assemblies, hence there is no guarantee of a consistent relative size within the VE. It is possible to always have a VIO that is larger than the artefact but whether this is practical is another matter.

\subsection{Icon}

Icons are more complex forms of shape (Shneiderman et al., 2010) or, to put it another way, icons consist of simple symbols that themselves consist of graphical elements (Horton, 1994). Well-designed icons can help users act quickly and surely, represent visual and spatial concepts, save space in the visual display and speed up search. They are also immediately recognised, provide better recall and do not rely on the user's ability to read (Horton, 1994). Icons still suffer from the problem of consistent differentiation from the engineering VE, however, a reasonably recognisable icon can move to counter this. For the reasons outlined, consideration of size, shape and icons alone is insufficient to generate the required visual distinctiveness.

\subsection{Line}

Lines have a number of practical uses in information visualisation depending on how they are configured and positioned (Shneiderman et al., 2010). The weight of a line can represent magnitude or importance, but users can struggle to discriminate between minor differences in line thickness. Line endings can be modified with dots, forks or arrow heads to encode distinct functions - source, destination, relationships, etc. Lines can be drawn as patterns (solid, dashed, dotted, etc.) and have specific meaning, as previously discussed, on engineering drawings for example $B S$ 8888:2004 (BSI Group, 2004).

\subsection{Text and typography}

Text and typography should be used sparingly as it can clutter a visualisation and can heavily influence the user's gaze when trying to interpret the visualisation (Dewar, 2012). In terms of font, Serif fonts are deemed better for blocks of texts and Sans-Serif for titles, tags and labels. Dewar (2012) also asks designers to be aware that writing in all-caps can take longer for the mind to process and adds unnecessary cognitive load for the user.

In three-dimensional VEs, text tends to fall into two categories, Internal and External Labels. Internal Labels or Surface Labels are most often associated with maps and are written on the surface of visual objects or spatially bound to an object (Vaaraniemi et al., 2013). They are frequently seen in the field of Biology where the names of parts of the body are written directly on the surface of the image (Hartmann et al., 2005). External Labels are more commonly associated with engineering drawings (BSI Group, 2004) with labels being placed surrounding the visual object and coupled with a connecting line to convey the relationship between label and object.

Gabbard et al. (2006) performed an analysis on the readability of text in AR and recommended the use of 'billboarding' text by placing it on a solid opaque background coloured to contrast with the colour of the text to help distinguish the text from the varying background. This technique may also help in engineering VEs. However, the work presented in Tatzgern et al. (2014) and Bell et al. (2001) shows how labels in three dimensions can quickly clutter the VE and become difficult to read without a good view management system in operation.

\subsection{Figure/Ground (Gestalt Principle)}

One of Gestalt's Principles of graphic design is Figure/Ground and it states that the mind separates the visual field into Figure (the foreground) and Ground (the background). Graphical User Interfaces use Figure/Ground with great effectiveness in the design of most desktop environments and applications. The placement of menus and other system features around the edges of the screen that open over the main focus of the screen separate the two. CAD systems use Figure/Ground in the same manner, with tool sets and systems menus all kept in the foreground and the artefact space/VE pushed to the background. 


\subsection{Consistency (Gestalt Principle)}

Another of Gestalt's Principles is Consistency, which when applied to VEs can be considered at two levels. In the first, consistency is key, regardless of the exact aspect of the display in question. Whether that be label and display elements (headers, footers, menus), dialogue, data visualisations, actions, functions, operations and even the positions of functional elements. Inconsistencies increase the cognitive load on the user and unnecessarily complicate the interaction and dissemination processes.

On the second level, inconsistency can be useful. In data visualisation inconsistencies can reflect and draw attention to inconsistencies in the data. With information visualisation within VEs, an inconsistency between the colour/size/shape of the VIO and the VE itself can emphasise the separation between the two visual elements and reduce the memory load.

\section{Engineering information markers in three-dimensional space}

Between 2015 and 2017 regular meetings and discussions took place between the authors of this paper and 10 Airbus engineers and project managers. These meetings took place at Airbus sites in Filton (UK), Bremen (Germany) and Toulouse (France) with the aim of determining the types of VIOs required within engineering VEs. These interactions were based around test bed systems (see Figure 1 and Jones et al., 2015), knowledge of existing CAD systems and 'real world' industrial use cases that focused on the types of information-based interactions that engineers have with three-dimensional product representations. Examples of these interactions include searching for product related reports, investigating clash detection/interference and general product related communication. Table 1 shows the information objects/interactions identified with example cases re-represented in the context of Formula Student perspective to maintain the confidentiality surrounding the Airbus examples. The goal then is to design a range of VIO, that encompass each of these information objects/interactions while adhering to good design practice and minimising the user effort required to find information.

Table 1. Information objects/interactions identified

\begin{tabular}{|c|c|c|}
\hline Interaction & Description & Example Usage \\
\hline Component & Single/Multiple product components. & $\begin{array}{l}\text { The remoulding of the driver seat to a new } \\
\text { driver. }\end{array}$ \\
\hline $\begin{array}{l}\text { System/ } \\
\text { Subsystem }\end{array}$ & $\begin{array}{l}\text { A collection of components that perform a } \\
\text { specific task. }\end{array}$ & The design and testing of the fuel system. \\
\hline Point & $\begin{array}{l}\text { A specific } \mathrm{x}, \mathrm{y} \text {, and } \mathrm{z} \text { coordinate within the } \\
\text { product coordinate system. }\end{array}$ & The location of a hole in the exhaust system. \\
\hline Vector & An indicator of movement or direction. & $\begin{array}{l}\text { Adjust the pedal position towards the forward } \\
\text { of the car to suit the driver's leg length. }\end{array}$ \\
\hline Layer & The geometric layers of a CAD model. & Removing the body work to inspect the chassis. \\
\hline Feature & Holes, chamfers, rounds, fillets, etc. & $\begin{array}{l}\text { Examine the bolt hole positions for } \\
\text { assembly/disassembly. }\end{array}$ \\
\hline Section & $\begin{array}{l}\text { A specific area covering of one or more } \\
\text { components. }\end{array}$ & $\begin{array}{l}\text { The aerodynamics testing of the front of the } \\
\text { car. }\end{array}$ \\
\hline Region & $\begin{array}{l}\text { A specific area that is not component } \\
\text { dependant. }\end{array}$ & $\begin{array}{l}\text { Corrosion along the training edges of the front } \\
\text { spoiler components. }\end{array}$ \\
\hline Surface & A single or collection of component surfaces. & Inspecting the quality of the paint. \\
\hline
\end{tabular}

\section{Implementation}

This section now introduces the test bed system developed and each of the VIOs proposed with a focus on how design theory is being applied. As with the use case examples in Table 1, a Formula Student racing car is used in the place of an Airbus artefact for the purposes of protecting confidentiality.

\subsection{Test bed system}

The test bed system is constructed using the JavaScript library three.js using a Formula Student (FS) Electric Racing car from the University of Bristol. The FS CAD model was extracted in a low detail 
STL format before being compressed using OpenCTM (Geelnard, 2010). The model consists of 201 individual components, totalling $451 \mathrm{~KB}$ in size. See Figure 1.

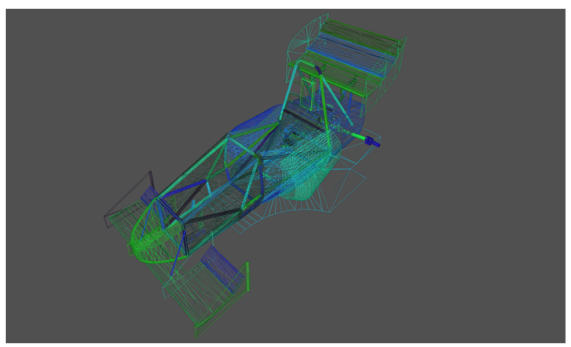

Figure 1. Test bed system

Table 2. Proposed four types of VIO

\begin{tabular}{|l|l|}
\hline \multicolumn{1}{|c|}{ Proposed VIO } & \multicolumn{1}{c|}{ Information Object } \\
\hline Point Of Interest (POI) & Point \\
\hline Point Of Interest (POI) (Directional) & Vector \\
\hline \multirow{2}{*}{ Component Of Interest (COI) } & Component \\
\cline { 2 - 2 } & System/Subsystem \\
\hline \multirow{2}{*}{ Region Of Interest (ROI) } & Layer \\
\cline { 2 - 2 } & Region \\
\cline { 2 - 2 } & Surface \\
\cline { 2 - 2 } & Feature \\
\hline Section Of Interest (ROI) & Section \\
\hline
\end{tabular}

\subsection{Visual Information Objects}

Based on the interactions identified in Section 5, this paper proposed four types of VIO: Points Of Interest (POI), Components Of Interest (COI), Region Of Interest (ROI) and Sections Of Interest (SOI). Table 2 shows each of these VIOs and the corresponding interaction covered.

\subsubsection{Point of Interest (POI)}

A Point of Interest represents a piece of information that relates to a single $\mathrm{x}, \mathrm{y}, \mathrm{z}$ position and can include a directional component. Examples include a hole in the exhaust (no direction) and instructions to move the seat forward (directed). Example of POIs exist in current market products such as the Google Maps pin (Svennerberg, 2010). The version in Figure 2 shows orange three-dimensional nondirectional markers and Figure 3 shows the directed version.

\subsubsection{Component of Interest (COI)}

Components of Interest were highlighted as a possible improvement on POIs (Jones et al., 2015) where a proof of concept using POIs was performed. COIs cover the component and system/subsystem techniques for CAD interaction. Figure 4 shows a piece of the front wing coloured pink/purple.

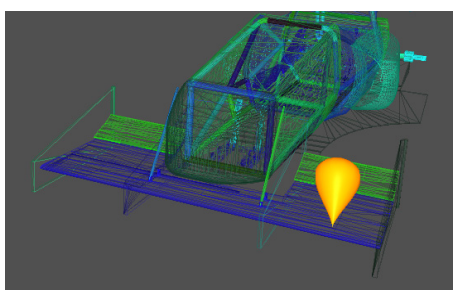

Figure 2. POI (Non-directional)

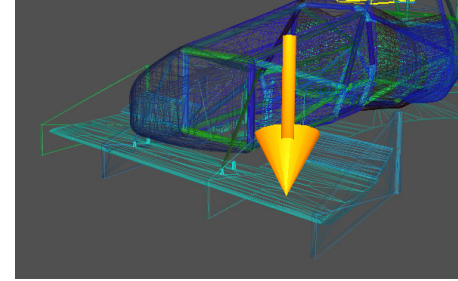

Figure 3. POI (Directional)

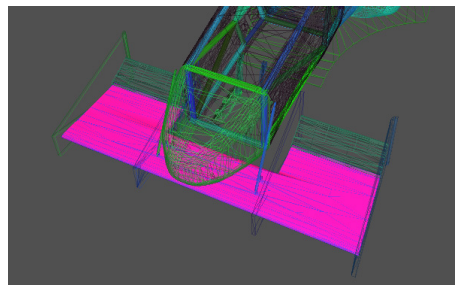

Figure 4. COI 


\subsubsection{Region of Interest (ROI)}

Regions of Interest are a direct requirement from industry following discussion of the need to be able to highlight a particular section on the surface of an artefact. For example, indicating corrosion across a section of single or multiple components. ROIs cover Layers, Regions, Surfaces and Features. Figure 5 show markers that would represent corrosion on the front spoiler of the car.

\subsubsection{Section of Interest (SOI)}

The concept of Sections of Interest was viewed in an industrial use case where engineers drag two and three-dimensional wire-frame boxes over regions of the product to select a range of components. Given the model is depicted using wire-frame, Figure 6 shows how the faces of the SOI are shaded but transparent to maintain visibility of the underlying model and still be primarily a three-dimensional wire-frame box.

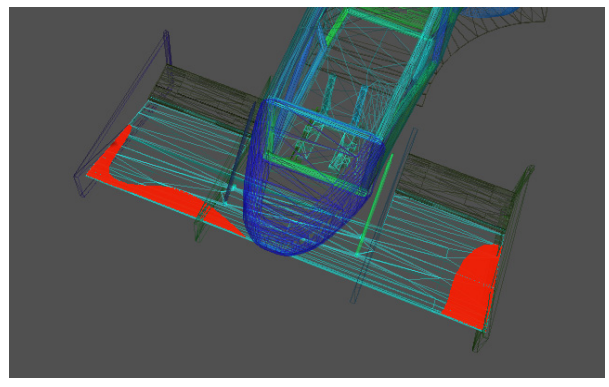

Figure 5. ROI

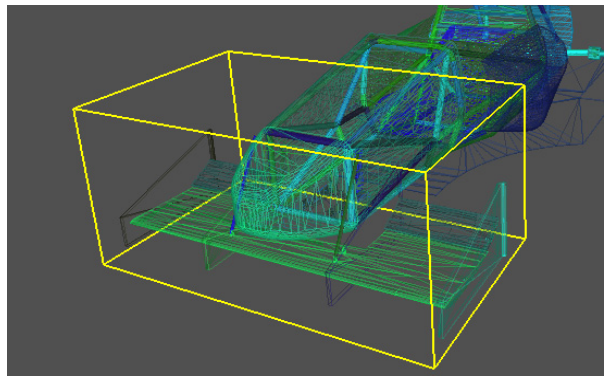

Figure 6. SOI

\section{Study}

Pnueli and Zussman (1997) discusses the evaluation of Human-Computer Interfaces for Information Retrieval and includes the importance of participants being the intended end users of the system. In line with this, a group of 32 engineers from both academia and industry participated in the study. The least qualified participants were third year students and current members of the Formula Student Bristol Electric Racing Team (two participants) or masters students (five participants). The remaining participants were either academics ranging from $\mathrm{PhD}$ to professorial level (14 participants) or currently working in the engineering industry (11 participants).

Participants were given a questionnaire showing screen shots of the five markers (shown in Figures 2, $3,4,5$ and 6) alongside a number of example information seeking scenarios (see Table 3). Screen shots were used to ensure users were focused on the markers themselves rather than other aspects of the system such as the navigation of the artefact space or system performance. Users were asked to rank the VIOs in the order which they would use the marker to represent each information source.

\section{Results}

Table 3 shows that VIOs ranked first and second for each of the Information Seeking Scenarios. For thoroughness the results were processed using three methods. The first using the percentage ranking, i.e. the number of people who ranked each marker first and second against the total number of participants. The second approach applied a score of 5 to 1 to each of the ranking positions ((position: score): $1: 5,2: 4,3: 3,4: 2,5: 1)$ and the total score for first and then second were summed. The third approach was derived from participant feedback where participants stated they sometimes struggled to differentiate between the ranking of two different markers and would score them equally if the questionnaire allowed. This approach sums the scores for first and second position and calculates the percentage against the total number of participants. Essentially this takes the mid-ranking point (third) and asserts that the two ranked above third position are preferred over the two ranked beneath third position. 
Table 3. Information sources and the highest two ranked VIOs

(Point-Of-Interest (POI) (D-Directional), Component-Of-Interest (COI), Region-OfInterest (ROI) and Section-Of-Interest (SOI))

\begin{tabular}{|c|c|c|c|c|c|c|c|}
\hline \multirow{4}{*}{\begin{tabular}{|l} 
Information Seeking Scenario \\
$\begin{array}{l}\text { Competition guidelines regarding a } \\
\text { part/system/sub-system }\end{array}$
\end{tabular}} & \multirow{3}{*}{\begin{tabular}{|c|} 
Position \\
$1 \mathrm{st}$ \\
\end{tabular}} & \multicolumn{6}{|c|}{ VIO } \\
\hline & & \multicolumn{2}{|c|}{ Percentage } & \multicolumn{2}{|c|}{ Score } & \multicolumn{2}{|c|}{$\begin{array}{c}\text { Total } 1 \mathrm{st}+2 \mathrm{nd} \\
(\%)\end{array}$} \\
\hline & & SOI & 50 & SOI & 80 & SOI & 69 \\
\hline & 2 nd & $\mathrm{CO}$ & 38 & $\mathrm{COI}$ & 48 & $\mathrm{COI}$ & 62 \\
\hline \multirow{2}{*}{$\begin{array}{l}\text { Details of the structural testing for a } \\
\text { part/system/sub-system }\end{array}$} & $1 \mathrm{st}$ & $\mathrm{RO}$ & 41 & ROI & 65 & $\mathrm{R}$ & 47 \\
\hline & $2 \mathrm{nd}$ & COI & 31 & $\mathrm{COI}$ & 40 & $\mathrm{COI}$ & 53 \\
\hline \multirow{2}{*}{$\begin{array}{l}\text { Damage report for a hole in a part/system/sub- } \\
\text { system }\end{array}$} & $1 \mathrm{st}$ & POI(D) & 50 & $\mathrm{POI}(\mathrm{D})$ & 80 & POI(D) & 72 \\
\hline & 2nd & $\mathrm{PO}$ & 47 & POI & 60 & $\mathrm{PO}$ & 66 \\
\hline \multirow{2}{*}{$\begin{array}{l}\text { Technical details for a part/system/sub-system } \\
\text { alignment adjustment }\end{array}$} & $1 \mathrm{st}$ & $\mathrm{CO}$ & 28 & $\mathrm{CO}$ & 45 & $\mathrm{CC}$ & 56 \\
\hline & 2nd & $\mathrm{CO}$ & 28 & $\mathrm{COI}$ & 36 & SO & 24 \\
\hline \multirow{2}{*}{$\begin{array}{l}\text { Aerodynamics report for a part/system/sub- } \\
\text { system }\end{array}$} & 1 st & $\mathrm{COI}$ & 53 & $\mathrm{COI}$ & 85 & $\mathrm{CC}$ & 88 \\
\hline & 2 nd & $\mathrm{COl}$ & 34 & $\mathrm{COI}$ & 44 & $\mathrm{RO}$ & 53 \\
\hline \multirow{2}{*}{$\begin{array}{l}\text { Damage report showing locations effected by } \\
\text { corrosion on a part/system/sub-system }\end{array}$} & 1 st & ROI & 88 & ROI & 140 & ROI & 88 \\
\hline & 2 nd & COI & 53 & $\mathrm{COI}$ & 68 & $\mathrm{COI}$ & 53 \\
\hline \multirow{2}{*}{$\begin{array}{l}\text { Livery and paint specifications for specific } \\
\text { part/system/sub-system }\end{array}$} & $1 \mathrm{st}$ & $\mathrm{COI}$ & 63 & $\mathrm{COI}$ & 100 & $\mathrm{CC}$ & 91 \\
\hline & $2 \mathrm{nd}$ & COI, ROI & 28 & COI, ROI & 36 & SOI & 50 \\
\hline
\end{tabular}

The results show that overwhelmingly the participants preferred the use of COIs for displaying the information sources with each of the other VIOs being used occasionally for specific purposes. Across the three methods of analysis, there was very little change in the highest two VIO rankings for each of the information sources with the results staying stable regardless of the method used and no difference at all between the first two methods. The main differences in the final analysis occur due to the approach preventing the same VIO appearing in both first and second position. This benefits the SOI marker in two of three cases with the ROI ranked second in the third case.

There is no definitive conclusion on the use of directional and non-directional POI markers. There appears to be a general preference for the directed version. On the occasion where they were ranked first and second, the directed version was ranked higher. However, the information source in this case was the position of damage (a hole) which means the directed marker was preferred for an information source that does not contain directional information. For the information source containing the directional information the COI was preferred followed by the directional POI.

\section{Conclusion}

This paper presented the design and verification of Visual Information Objects (VIOs), visual markers that indicate the presence of information within a three-dimensional Engineering Virtual Environment. Five marker designs were developed based on input from 10 Airbus engineers and project managers and a range of user and design considerations. The resultant VIOs were then verified using 32 engineers from both academia and industry using a series of information seeking scenarios.

The overwhelming conclusion from the results is that engineers prefer to use Component Of Interest (COI) markers (based of the artefact components themselves) for the displaying information. One could argue that this is the result of the engineer's familiarity with CAD and the associated interactions with the artefact model that are reproduced by the COI marker. Further work would be required to validate this, although the finding does reflect the notion that engineers think visually and functionally in-line with the artefacts that they design and build.

Secondary to the COI marker preference was the finding that there are scenarios where each of the other VIOs are preferred. This demonstrates both the need for a range of markers and verifying the design process which leads to their development.

The Point Of Interest (POI) markers warrant further study given the results show no preference for one version over the other. This lack of definitive preference could stem from the fact that there are no 'real- 
world' engineering artefacts/features that exist with a single three-dimensional co-ordinate and no geometric shape. The COI, Region Of Interest (ROI) and Section Of Interest (SOI) are all directly related to the geometric shape of the artefact where as the POI has no 'real-world' equivalent. One study participant commented that they interpreted the Directional POI as a Point Load and as such there is an argument that one would use the marking for testing data. This is however speculative and further research is required. Consequentially, while it is reasonable to assert that any intended use could be learned during the use of an artefact-based information navigation system however, at the very least, a note should be made of the possible ambiguity around their general use if they are too be used prior to this research being performed.

\section{Future work}

The Visual Information Object (VIO) designs developed in this paper are only one step in developing a system that enables engineers to navigate information via the artefact structure. Other examples include how documents are related to the artefact (Jones et al., 2016) and how the user interacts with the artefact to name two examples.

Another such aspect that is closely related to the VIO design is a Layer-Of-Detail (LOD) strategy. As the number of information sources increases, the virtual environment is at risk of becoming visually cluttered. This would make the system unusable and, as the user zooms out from the artefact, small markers could shrink to the point where they become too small to be visible. An LOD strategy manages these by, for example, clustering markers into one more visible marker that identifies itself as a cluster of other markers. Figure 7 shows an example of such marker. The LOD strategy decides the optimal point to cluster based on the distance between the camera and marker or between neighbouring markers. See Figures 8, 9, 10 and 11. There is still then a little work to be done before the visualisation of information within engineering virtual environments is complete.

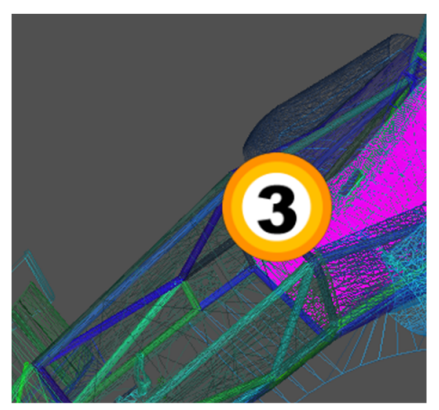

Figure 7. An example of a cluster marker

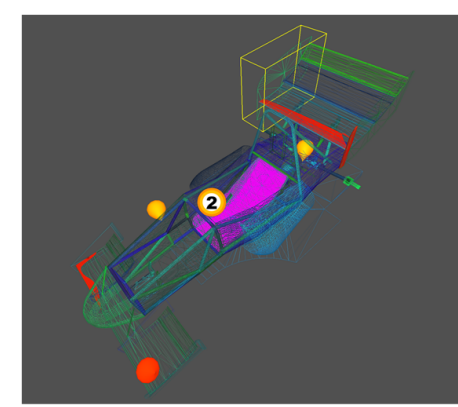

Figure 8. An LOD strategy in action

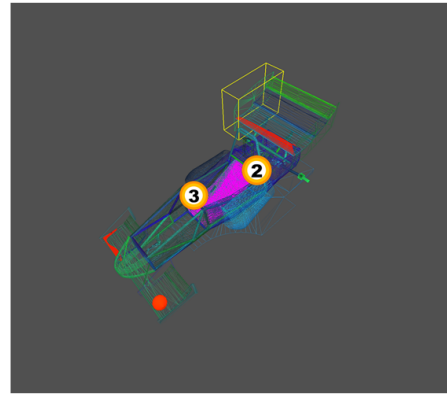

Figure 9. An LOD strategy in action

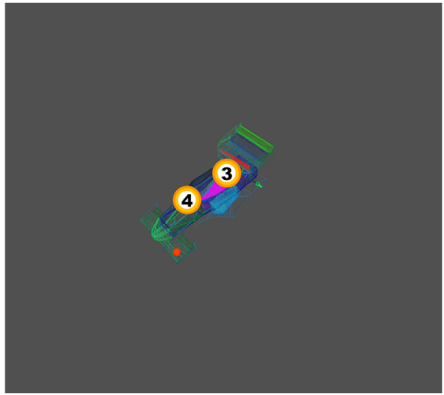

Figure 10. An LOD strategy in action

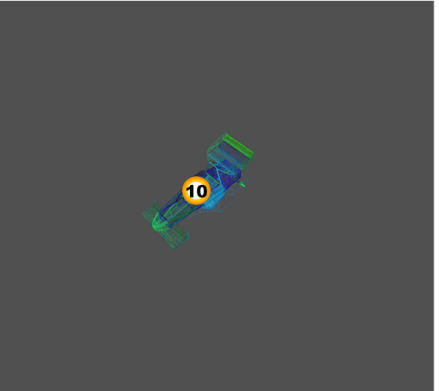

Figure 11. An LOD strategy in action

\section{Acknowledgements}

This work is funded via an EPSRC CASE AWARD, the Language of Collaborative Manufacturing (LOCM) project (EPSRC grant reference EP/K14196/1) and the Airbus Group. 


\section{References}

Allen, R.D., Hicks, B.J. and Culley, S.J. (2000), "Integrating electronic information for the design of mechanical systems: the designer's perspective", Proceedings of the World Multiconference on Systemics, Cybernetics and Informatics (SCI 2000), Orlando, FL, July 23-26, 2000, International Institute of Informatics and Systemics, pp. 266-271.

Ameri, F. and Dutta, D. (2005), "Product lifecycle management: closing the knowledge loops", Computer-Aided Design and Applications, Vol. 2 No. 5, pp. 577-590. https://doi.org/10.1080/16864360.2005.10738322

Bell, B., Feiner, S. and Höllerer, T. (2001), "View management for virtual and augmented reality", Proceedings of the 14th Annual ACM Symposium on User Interface Software and Technology, Orlando, FL, November 1114, 2001, pp. 101-110. https://doi.org/10.1145/502348.502363

BSI Group (2004), BS 8888:2004 Technical product specification (TPS). Specification, BSI, London. https://doi.org/10.3403/03109087

Department for Transport (2009), Traffic Signs Manual (Eighth Impression), Her Majesty’s Stationery Office, London.

Dewar, M. (2012), Getting Started with D3: Creating Data-Driven Documents, O’Reilly Media, Inc., Sebastopol.

Ding, L., Davies, D. and McMahon, C.A. (2009), “The integration of lightweight representation and annotation for collaborative design representation", Research in Engineering Design, Vol. 20 No. 3, pp. 185-200. https://doi.org/10.1007/s00163-008-0052-3

Doil, F., Schreiber, W., Alt, T. and Patron, C. (2003), "Augmented reality for manufacturing planning", Proceedings of the Workshop on Virtual Environments 2003 (EVGE '03), Zurich, Switzerland, May 22-23, 2003, pp. 71-76. https://doi.org/10.1145/769953.769962

Ellis, S.R. (1991), "Nature and origins of virtual environments: A bibliographical essay", Computing Systems in Engineering, Vol. 2 No. 4, pp. 321-347. https://doi.org/10.1016/0956-0521(91)90001-L

Ellis, S.R. (1994), "What are virtual environments?", IEEE Computer Graphics and Applications, Vol. 14 No. 1, pp. 17-22. https://doi.org/10.1109/38.250914

Few, S. (2006), Common pitfalls in dashboard design. [online] Perceptual Edge. Available at: http://www.perceptualedge.com/articles/Whitepapers/Common_Pitfalls.pdf

Gabbard, J.L., Swan, J.E. II and Hix, D. (2006), "The effects of text drawing styles, background textures, and natural lighting on text legibility in outdoor augmented reality", Presence: Teleoperators and Virtual Environments, Vol. 15 No. 1, pp. 16-32. https://doi.org/10.1162/pres.2006.15.1.16

Galitz, W.O. (2007), The Essential Guide to User Interface Design: An Introduction to GUI Design Principles and Techniques, John Wiley \& Sons, New York.

Geelnard, M. (2010), OpenCTM, the open compressed triangle mesh file format. [online] Available at: http://openctm.sourceforge.net/

Giess, M.D., Wild, P.J. and McMahon, C.A. (2008), "The generation of faceted classification schemes for use in the organisation of engineering design documents", International Journal of Information Management, Vol. 28 No. 5, pp. 379-390. https://doi.org/10.1016/j.ijinfomgt.2007.10.001

Hartmann, K., Götzelmann, T., Ali, K. and Strothotte, T. (2005), "Metrics for functional and aesthetic label layouts", Proceedings of the 5th International Symposium on Smart Graphics, Frauenwörth Cloister, Germany, August 22-24, 2005, pp. 115-126. https://doi.org/10.1007/11536482_10

Hawking, D. (2004), "Challenges in Enterprise Search", Proceedings of the 15th Australasian Database Conference (ADC 2004), Dunedin, New Zeland, January 18-22, 2004, pp. 15-24.

Hicks, B.J., Culley, S.J., Allen, R.D. and Mullineux, G. (2002), "A framework for the requirements of capturing, storing and reusing information and knowledge in engineering design", International Journal of Information Management, Vol. 22 No. 4, pp. 263-280. https://doi.org/10.1016/S0268-4012(02)00012-9

Horton, W.K. (1994), The Icon Book: Visual Symbols for Computer Systems and Documentation, John Wiley \& Sons, Inc., New York.

Iliinsky, N. and Steele, J. (2011), Designing Data Visualizations: Representing Informational Relationships, O’Reilly Media, Inc., Sebastopol.

Jayaram, S., Jayaram, U., Wang, Y., Tirumali, H., Lyons, K. and Hart, P. (1999), "VADE: A virtual assembly design environment", IEEE Computer Graphics and Applications, Vol. 19 No. 6, pp. 44-50. https://doi.org/10.1109/38.799739

Jones, D.E., Chanchevrier, N., McMahon, C., Hicks, B. (2015), “A Strategy for Artefact-Based Information Navigation in Large Engineering Organisations", Proceedings of the 20th International Conference on Engineering Design (ICED 15) Vol 10: Design Information and Knowledge Management Milan, Italy, July 27-30, 2015. https://doi.org/10.1007/978-3-319-33111-9_20

Jones, D.E., Xie, Y., McMahon, C., Dotter, M., Chanchevrier, N. and Hicks, B. (2016), “Improving enterprise wide search in large engineering multinationals: A linguistic comparison of the structures of internet-search 
and enterprise-search queries", Revised Selected Papers of the 12th IFIP WG 5.1 International Conference (PLM 2015), Doha, Qatar, October 19-21, 2015, pp. 216-226. https://doi.org/10.1007/978-3-319-33111-9_20

Kim, S. and Weissmann, D. (2006), "Middleware-based integration of multiple CAD and PDM systems into virtual reality environment", Computer-Aided Design and Applications, Vol. 3 No. 5, pp. 547-556. https://doi.org/10.1080/16864360.2006.10738408

Li, C., McMahon, C. and Newnes, L. (2009), “Annotation in Design Processes: Classification of Approaches", Proceedings of 17th International Conference on Engineering Design (ICED 09), Vol. 8, Design Information and Knowledge, Palo Alto, CA, USA, August 24.-27, 2009, pp. 251-262.

Liarokapis, F., Mourkoussis, N., White, M., Darcy, J., Sifniotis, M. et al. (2004), "Web3D and augmented reality to support engineering education", World Transactions on Engineering and Technology Education, Vol. 3 No. 1, pp. 11-14.

Liu, D.T. and Xu, X.W. (2001), "A review of web-based product data management systems", Computers in Industry, Vol. 44 No. 3, pp. 251-262. https://doi.org/10.1016/S0166-3615(01)00072-0

Maxfield, J., Fernando, T. and Dew, P. (1995), “A distributed virtual environment for concurrent engineering”, Proceedings of the Virtual Reality Annual International Symposium, Research Triangle Park, NC, USA, March 11-15, 1995, pp. 162-170. https://doi.org/10.1109/VRAIS.1995.512492

McAlpine, H., Hicks, B.J., Huet, G. and Culley, S.J. (2006), "An investigation into the use and content of the engineer's logbook", Design Studies, Vol. 27 No. 4, pp. 481-504. https://doi.org/10.1016/j.destud.2005.12.001

McMahon, C.A. and Davies, D. (2006), "The use of annotation in design representation", Proceedings of the 5th International Seminar and Workshop of Engineering Design Integrated Product Development (EDIProD 2006), Zielona Góra, Poland, September 21-23, 2006, pp. 105-111.

Pirolli, P. and Card, S. (1999), "Information foraging", Psychological Review, Vol. 106 No. 4, pp. 643-675. https://doi.org/10.1037/0033-295X.106.4.643

Pnueli, Y. and Zussman, E. (1997), "Evaluating the end-of-life value of a product andimproving it by redesign", International Journal of Production Research, Vol. 35 No. 4, pp. 921-942. https://doi.org/10.1080/002075497195452

Rangan, R.M. and Chadha, B. (2001), "Engineering information management to support enterprise business processes", Journal of Computing and Information Science in Engineering, Vol. 1 No. 1, pp. 32.40. https://doi.org/10.1115/1.1353845

Shneiderman, B., Plaisant, C., Cohen, M. and Jacobs, S. (2010), Designing the User Interface: Strategies for Effective Human-Computer Interaction, Pearson Education.

Smith, S.L. and Mosier, J.N. (1984), Design Guidelines for User-System Interface Software, The MITRE Corporation, Bedford, MA.

Stark, J. (2015), "Product lifecycle management", In: Stark, J. (Ed.), Product Lifecycle Management, Springer, London, pp. 1-16. https://doi.org/10.1007/978-0-85729-546-0_1

Svennerberg, G. (2010), Beginning Google Maps API 3, Apress, New York. https://doi.org/10.1007/978-1-43022803-5

Tatzgern, M., Kalkofen, D., Grasset, R. and Schmalstieg, D. (2014), "Hedgehog labeling: View management techniques for external labels in 3D space", Proceedings of 2014 iEEE Virtual Reality (VR) Minneapolis, MN, USA, March 29-April 2, 2014, pp. 27-32. https://doi.org/10.1109/VR.2014.6802046

Tursi, A., Panetto, H., Morel, G. and Dassisti, M. (2009), “Ontological approach for products-centric information system interoperability in networked manufacturing enterprises”, Annual Reviews in Control, Vol. 33 No. 2 , pp. 238-245. https://doi.org/10.1016/j.arcontrol.2009.05.003

Vaaraniemi, M., Freidank, M. and Westermann, R. (2013), "Enhancing the visibility of labels in 3d navigation maps", In: Pouliot, J., Daniel, S., Hubert, F. and Zamyadi, A. (Eds.), Progress and New Trends in 3D Geoinformation Sciences, Springer, Heidelberg, pp. 23-40.

Webster, A., Feiner, S., MacIntyre, B., Massie, W. and Krueger, T. (1996), "Augmented reality in architectural construction, inspection and renovation", Proceedings of the Third Congress on Computing in Civil Engineering, Anaheim, CA, USA, June 17-19, 1996, pp. 913-919.

Xie, Y., Culley, S. and Weber, F. (2011), "Applying context to organize unstructured information in aerospace industry”, Proceedings of the 18th International Conference on Engineering Design (ICED 11), Vol. 6: Design Information and Knowledge, Lyngby/Copenhagen, Denmark, August 15-19, 2011, pp. 424-435.

David Edward Jones, Research Associate

University of Bristol, Mechanical Engineering

Queen's Building, BS8 1TR Bristol, United Kingdom

Email: david.jones@bristol.ac.uk 